\title{
Utilisation of the Internet for Cyberloafing Activities among University Students
}

\author{
Rosemary Twum ${ }^{1}$, Christopher Yarkwah ${ }^{1}$, Ivy Kesewaa Nkrumah ${ }^{1 *}$
}

${ }^{1}$ University of Cape Coast, GHANA

*Corresponding Author: ivy.nkrunmah@ucc.edu.gh

Citation: Twum, R., Yarkwah, C., \& Nkrumah, I. K. (2021). Utilisation of the Internet for Cyberloafing Activities among University Students. Journal of Digital Educational Technology, 1(1), ep2101. https://doi.org/10.21601/jdet/10912

\section{ARTICLE INFO}

Received: 1 Apr. 2021

Accepted: 23 Apr. 2021

\begin{abstract}
Cyberloafing, described as students use of the internet for non-class related purposes during the instructional period, has been shown to have significant negative influence on scholastic attainments (e.g., Wu, Mei \& Ugrin, 2018). As the practice of cyberloafing becomes entrenched, students are likely to carry such behaviours to their workplaces, and subsequently affect performance and productivity of the labour force. This study explored cyberloafing activities among university students. The parameters of investigation were the frequency, kinds, gender issues and the factors that give birth to cyberloafing during the instructional period. The study employed the descriptive survey design and questionnaire was used for data collection. A total of 140 students randomly selected from the University of Cape Coast, Ghana, participated in the study. The findings were that cyberloafing is pervasive among university students. However, student cyberloafing engagements are predominantly narrowed to specific activities such as online-chatting, listening to the news and sending and receiving emails. Respondents further indicated varied reinforcers of cyberloafing emerging from the actions of lecturers, learners, the course and the learning environment. It was recommended that the university, in collaboration with stakeholders adopt effective ways to curb the current phenomenon of cyberloafing in schools before they turn into unmanageable behaviours.
\end{abstract}

Keywords: cyberloafing, internet, distraction, multitasking

\section{INTRODUCTION}

The use of the internet and its attendant devices are currently being adopted and utilised in almost all organisations and institutions worldwide. Internet mediums have reformed communication, entertainment, work, and education by serving as a platform where individuals can share information promptly, interact from almost anywhere on the globe and learn remotely irrespective of time and location. Thus, the internet provides a great deal of opportunities and a significant leverage to individuals and organisations alike by offering a fierce edge and a gateway to the global marketplace. Internet technology has gradually become a part of university educational experience and higher education institutions worldwide, employ the internet in nearly all facets of their educational engagements (Yilmaz et al., 2015). Internet technology has also been shown capable of improving teaching and learning as well as students' involvement in school activities (Marshall, 2016; Raja \& Nagasubramani, 2018; Ryan et al., 2000) such that the modern-day university student is more connected in and out of the classroom than ever. During instructional sessions, students are faced with varied tasks including note taking, answering questions and completing assignments. These tasks were remotely done by students in the past, but the advent of technology-driven tools has shifted a greater part of such burden from students to internet technology and this has further provoked transformation in teaching and learning as well as enhanced productivity in the educational settings (Yebowaah, 2018). More importantly, the use of the internet has assisted in shaping the former teachercentered and textbook controlled approach into a more productive, learner-centered approach where there are problem-solving skills, engagements, collaborative and personalized learning (see Chawinga, 2017).

Currently, it is common for university students to attend classes with their internet-connected devices such as smartphones, tablets and laptops. Students employ such devices for both class related and non-class related purposes (Ragan et al., 2014), and quite often divide their attention between more than one task, such as checking social media updates, or updating their status whiles lecture is ongoing (see, Almasi, Machumu, \& Zhu, 2017; Kolan 2018; Saritepeci, 2019; Glass \& Kang, 2019). Most students assume that they can multitask, but because it is very difficult to divide attention equally between two tasks; student's attention to the lecture 
suffers in most cases. Non-class related activities distract students focus in general and in particular, their learning. If a student engages in internet-mediated activities (that his or her lecturers do not consider lesson-related) during lectures, it is described as cyberloafing (e.g., Gerow et al., 2010). Cyberloafing was initially identified in organisational settings and has attracted the attention of organisational researchers. It is a common subject of business and management and it is professed as a counterproductive divergent conduct in the workplace. Cyberloafing is a deviant workplace behavior, which is a form of production deviance, as employees misuse their time during office hours on non-work-related online activities (Jandaghi et al., 2015; Lim, 2002), such as browsing social networking sites, playing online games, watching online videos, and sending personal messages. Cyberloafing behaviours have extended beyond organisational settings into the school environment. Gerow et al. (2010) considered examples of school related cyberloafing activities as including playing online games, sending and receiving emails, updating status on social media and watching videos online (see also, Brubaker, 2006; Dursun \& Akbulut, 2018; Kalayci, 2010). In this study, the term cyberloafing is operationalised as students use of the internet for extraneous, irrelevant, activities during the instructional period.

Cyberloafing has been shown to have significant negative effects on the learning environment (Lim, 2002; see also, Dursun \& Akbulut, 2018; Karaoglan-Yilmaz et al., 2015; Taneja, Fiore, \& Fischer, 2015; Wu, Mei, \& Ugrin, 2018); it interrupts students' study time (Nwakaego \& Angela, 2018; Taneja, Fiore, \& Fischer, 2015), serves as a distraction (Hembrooke \& Gay, 2013; Ravizza et al., 2017), impact negatively on student's attention and ability to focus (Alhami, 2018), inhibits deeper learning (Heflin et al., 2017) and hamper academic performance (Rivazza, Uitlugt, \& Fenn, 2017; Yılmaz et al., 2015; Wu et al., 2018). Other studies have equally reported that cyberloafing can be distracting and detrimental to students' academic engagements as well as frustrating for instructors (Hembrooke \& Gay, 2003; Ravizza et al., 2013). Some lecturers even suspend students from their lessons when it happens because it distracts both the student, their colleagues and the instructor. The incidence of cyberloafing activities in schools are however likely to increase, because of the improvements in instant accessibility to internet and mobile technologies. As the practice of cyberloafing becomes entrenched, students are likely to carry such behaviours to their workplaces, and subsequently affect performance and productivity of the labour force. Currently, there is an upsurge of research on cyberloafing in the school context and a significant number of studies have been reported on the phenomenon (Coskun \& Gokcearslan, 2019; Saritepeci, 2020), but most of the extant empirical studies were conducted in the Asia, Western and the Oceania. There is a large paucity of research in this area from Africa, particularly, Ghana. Meanwhile, Boakye and Banini (2008) has indicated that the use of the internet is becoming more popular among the youth in the Ghanaian society. Owing to cultural and social orientations, there exist significant differences between students in Ghana and other parts of the world. Such ecological variations shape individuals' thoughts, preferences and attitude. Hence, it will be difficult to conveniently generalise the results of cyberloafing research gathered elsewhere to the Ghanaian society. The present study thus explored cyberloafing activities among university students in Ghana. The chief objectives of the study were to: (1) examine the extent to which students engage in cyberloafing (2) explore the kinds of cyberloafing activities that students partake in (3) examine the reasons students partake in cyberloafing activities (4) determine the level of student's involvement in cyberloafing activities on the basis of gender.

\section{METHODS}

\section{Design}

The research adopted the descriptive survey design as it aimed at casting light on the present phenomenon of cyberloafing through a process of data collection that helps the researchers to describe the situation comprehensively than will be possible without using this method (Fox, 2007). A selfstructured questionnaire, consisting of closed-ended and open-ended items was the main instrument for the study. The questionnaire was used for both quantitative and qualitative purposes in collecting data. The research instrument consisted of four sections (A-D). Section "A" was meant to elicit demographic data of respondents in addition to two questions on duration and frequency of internet use among respondents on a daily basis. Sections B and C sought for information on the kinds of cyberloafing activities learners participated in during lectures and the reasons students engaged in cyberloafing respectively. Finally, Section D explored the frequency of cyberloafing among students on the basis of gender.

\section{Selection of Participants}

The target population for the study were levels 300 and 400 students pursuing B.Ed Computer Science and B.Ed Mathematics programmes at the University of Cape Coast. The population of the students was 401 and out of this population size, 200 were sampled as respondents (Krejcie \& Morgan, 1970). Levels 400 and 300 students were of interest in this study because cyberloafing has been cursorily identified in such levels. Levels 100 and 200 students were likely to already have some anxiety as they were still fairly new in the tertiary system and might least engage in non-lecture related actions during lessons. The study used the simple random sampling technique (specifically, the computerised lottery method) to select the respondents. Each of the 401 students was assigned a number between 1 and 401, after which 200 of those numbers were randomly picked.

\section{Procedure}

The researchers initially introduced themselves to the participants. The participants were told that the study was meant to gather information about their use of the internet in school, and in particular during lessons. They were assured of anonymity of their responses and this was further emphasised in print on the questionnaire. The questionnaires were distributed by the researchers among the identified respondents and they were given one day to complete the questionnaires and return them to the researchers at an agreed 
place. The return rate of the total questionnaires distributed was 70 percent (140 questionnaires).

\section{Data analysis}

The data that were collected were organised, coded and analysed. Serial numbers and coding system were developed on the items in the questionnaires. The obtained data were analysed using the qualitative research method of content analysis for open-ended items from the questionnaire. The researcher gathered similar data under certain concepts and themes; and then interpreted them by organisation. The analysis of the main results highlighted the actual research questions in the study. Descriptive statistics was used to analyse the data to provide results. Frequencies and percentages were used to analyse the three research questions to make data meaningful for easy interpretation. Data was presented in the form of tables for easy understanding. The results are presented and discussed in the subsequent sections.

\section{RESULTS AND DISCUSSION}

\section{Preliminary Analysis}

Analysis of the background data of respondents revealed that 112 (80.0\%) were males and the remaining 38 (20\%) were females. Sixty-six (47.1\%) of the respondents were in level 300 while 74(52.9\%) were in level 400. Further, 100 (71.4\%) were B.Ed (Mathematics) students whereas 40 ( 28.6\%) were B.Ed (Computer Science) students. Regarding the duration of Internet use on a daily basis, 6 (4.3\%) respondents reported that they use the internet less than one hour a day, 13 (9.3\%) between 1 and 2 hours, 26 (18.6\%) between 2 and 3 hours, 57 (40.7\%) between 3 and 5 hours and 38 (27.1\%) more than 5 hours a day. The respondents were also asked to indicate their frequency of Internet use every day; 20 (14.3\%) reported that they use it less than 5 times, 44 (31.4\%) between 6 to 10 times, 30 (21.4\%) between 11 and 20 times, 31 (22.1\%) between 21 and 30 times, and 15 (10.7\%) more than 31 times. The aforementioned results provide a fair knowledge on the availability and use of the internet among students. The results show that more students get involved in cyber activities on a daily basis and tend to spend an average of 3 hours or more on the internet in a day. Students use of the internet reported in Section A questions 4 and 5 subsumed both inclass and out-of-class cyber activities including school related and non-school related cyber actions. Finally, question 6 of Section A required students to indicate the frequency of use of the internet for non-class related purposes (cyberloafing) during lectures. Most of the respondents 57 (43.2\%) indicated that they engage in nonrelated cyber activities during lectures often, whereas 38 (28.8\%) showed that they do it very often. Only a small proportion of respondents 41 (29.3\%) mentioned that they never engage in such actions during lectures, 5 (3.8\%) stated doing it on rare occasions whereas 26 (19.7\%) said sometimes. Here it is clear that the 'very often' and 'often' responses is more than about $71 \%$, indicating that more students engage in cyberloafing activities during lectures. Based on the results here, it can be concluded that the level of knowledge access by students via the internet during the teaching-learning process is high. Students are definitely utilizing the internet during their education and the teachinglearning process. In a related study, it was reported that in Turkey, most university students at the graduate level (87.5\%) use the internet (TUIK, 2009) and out of this number, $82 \%$ of students stated that they cannot bear the thought of daily life without access to the internet. The rest of the data reported in the subsequent research questions hinges on the kinds, reasons and gender issues in cyberloafing among respondents.

\section{Research Question 1: What Cyberloafing Activities Do} University Students Participate in during Lectures?

The first research question sought to identify the specific kinds of cyberloafing activities students participate in during the instructional period. The results are presented in Table 1.

Foremost, Table 1 indicate that more than half of the respondents reported engaging in one kind of cyber actions or more, during lectures. The various cyberloafing activities respondents reported on included chatting online, using social networking sites and downloading lecture materials, checking and sending emails, visiting entertainment sites, watching sports and uploading pictures. The highly ranked cyberloafing activities were the online chatting 122 (87.1\%), visiting social networking sites 99 (70.7\%), browsing the internet for information unrelated to lecture 89 (63.6) and reading news 85 (60.7\%), and then checking emails 73 (52.1\%). These activities are somewhat semantically related as social actions and that manifests the characteristically friendly, chatty and sociable nature of Ghanaians. Ghanaian youth grow up in close knit communities and often show concerns for families and friends through regular communication with such groups. The current trend of ethnic and global migration which were assumed to have threatened the Ghanaian traditional family culture, appears to be resolved by the influx of the internet. For example, Ocansey, Ametepe and Oduro (2018) reported that the contemporary Ghanaian youth is attached to social media and most of them use the facility for building friendships and communicating with family both offline and online, entertaining themselves, building their own content, discovering their self-identities and developing their selfesteem (Ocansey, Ametepe, \& Oduro, 2018). Thus, the internet helps to maintain and enhance communication and social identity of the Ghanaian youth by means of social networks (see, Lim \& Chen, 2012). In a related study, Varol and Yıldırım (2019) found university students to be engaged in cyberloafing activities such as checking emails, reading online news, visiting social network pages as well as downloading materials from the internet. In general, it appears university students in the aforementioned literature appear to largely rely on the internet for the common use of online chatting, reading news, visiting social networking sites. Shopping 1 (0.7\%), making online banking transactions 7 (5.0\%), playing online games 8 (5.7\%) and watching videos or movies 11 (7.9\%) as well as listening to music 10 (7.1\%) were the least cyberrelated actions that student conducted during lectures. These findings are consistent with a research conducted in 2012, where shopping online, looking for employment, and playing online games were the least prevalent activities but were rated the most serious (Lim \& Chen, 2012). Online shopping in Ghana is very much in its emergence stage and the patronage is low as most Ghanaians tend to maintain the remote culture 
Table 1. Cyberloafing Activities that Students Engage in

\begin{tabular}{|c|c|c|c|c|}
\hline \multirow[b]{2}{*}{ Statements } & \multicolumn{2}{|c|}{ Yes } & \multicolumn{2}{|c|}{ No } \\
\hline & $\mathrm{F}$ & $\%$ & $\mathrm{~F}$ & $\%$ \\
\hline I visit social networking sites during lectures. & 99 & 70.7 & 41 & 29.3 \\
\hline I chat online during lectures. & 122 & 87.1 & 18 & 12.9 \\
\hline I play online games during lectures. & 8 & 5.7 & 132 & 94.3 \\
\hline I visit sports sites during lectures. & 53 & 6.8 & 20 & 15.2 \\
\hline I visit entertainment sites when I am at lectures. & 66 & 47.1 & 74 & 52.9 \\
\hline I watch videos/movies during lecture hours. & 11 & 7.9 & 129 & 92.1 \\
\hline I listen to music when I am at lectures. & 10 & 7.1 & 130 & 92.9 \\
\hline I take pictures and post them on my status during lectures. & 25 & 17.9 & 115 & 82.1 \\
\hline I make online banking transactions during lectures. & 7 & 5.0 & 133 & 95.0 \\
\hline I visit finance website during lectures. & 20 & 14.3 & 120 & 85.7 \\
\hline I check/send emails during lectures. & 73 & 52.1 & 67 & 47.9 \\
\hline I download materials during lectures. & 77 & 55.0 & 63 & 45.0 \\
\hline I browse the internet for information unrelated to the lectures. & 89 & 63.6 & 51 & 36.4 \\
\hline I read news from the internet during lectures. & 85 & 60.7 & 55 & 39.3 \\
\hline I upload my pictures on social networks during lectures. & 38 & 27.1 & 102 & 72.9 \\
\hline I shop online during lectures. & 1 & 0.7 & 139 & 99.3 \\
\hline
\end{tabular}

of face-to-face shopping, perhaps a reason shopping online attracted the least rating. The university communicates to students through emails and sometimes certain information get to students late. Most students have therefore developed the habit of checking their university mails quite often in order not to miss out on vital information. Downloading materials 77 (55\%) from the internet is actually not an academic threat because there are few books in the university library and most students depend on e-books for academic survival. However, what makes this action threating is the fact that it is done when an instructor is in action thereby derailing the student's cognitive resource which is needed for the instructional session. In summary, research question 1 makes obvious claims that cyberloafing activities such as watching movies, playing games online, taking pictures, making online banking transactions, visiting financial websites, shopping online and uploading pictures on social networks during class hours are not popular amongst Ghanaian students. The common cyberloafing activities amongst Ghanaian students are rather online chatting, visiting social networking sites, reading the news and visiting entertainment sites.

\section{Research Question 2: Why Do Students Partake in Cyberloafing Activities during Lectures?}

The second research question sought to elicit information from respondents on the reasons they partake in cyberloafing activities during lectures. The four thematic areas reported on are; reasons associated with the lecturer, reasons associated with learners, reasons inherent in the course and the reasons associated with the learning environment. The results are presented in Table 2.

From Table 2, the lecturer related factors that respondents predominantly cited as reasons for engaging in cyberloafing were; limited methods of teaching, limited use of teaching and learning materials (TLMs), unpreparedness of lecturers and less student engagements. It is worth noting that the main teaching method employed in the university is the lecture method, and this method is teacher controlled and information centered. In the lecture method, the teacher works as a role resource in classroom instruction and is more active in talking and the student is quite a passive listener. This creates a somewhat dullness in the classroom as the interaction between the learner and the teacher is quite limited (Muganga \& Ssenkusu, 2019) and that explains why students may feel disengaged and subsequently resort to cyberloafing. Regarding the ineffective use of TLMs, most faculties in Ghanaian universities are resource constrained and the lecturer has to verbally explain sometimes concrete issues. Even some scientific topics which should be treated in the laboratory are taught in the classrooms via lectures because the universities are not well resourced which herein is seen as a drive for cyberloafing. Poor teacher preparation is considered as a mystery by some authors (Goldhaber, 2002). Porter and Brophy (1988) in their study on the synthesis of research on good teaching listed that effective teachers are clear about their instructional goals, are knowledgeable about the content, communicate well, monitor students' understanding, are thoughtful and respectful about their teaching practices. However, in a study on conceptions of effective teaching, Saroyan, Dagenais, and Zhou (2009) found out that students expressed four ideas about effective teaching. Effective teachers have knowledge, prepare and manage instruction, promote learning and help students grow so they can learn independently. If such indicators are unmet for any instruction, students conclude on poor teacher preparation. The indicators of poor teacher preparation identified in this study were extracted from the behaviours teachers exhibited in the classroom such as unclear goals, incoherent lesson and inadequate knowledge of the subjectmatter. Poor content knowledge, and lateness were other minor issues respondents listed as part of the lecturer-related factors that promote cyberloafing. The learner-inherent factors that respondents mentioned were largely distraction, boredom and 
Table 2. Reasons Students Engage in Cyberloafing

\begin{tabular}{|c|c|c|}
\hline & Statement & Frequency \\
\hline \multirow{13}{*}{$\begin{array}{l}\text { Reasons } \\
\text { associated } \\
\text { with lecturer }\end{array}$} & Does not teach well & 25 \\
\hline & Poor content knowledge & 16 \\
\hline & Limited methods of teaching & 55 \\
\hline & Unpreparedness for lesson & 34 \\
\hline & Ineffective use of TLMs & 23 \\
\hline & Poor personality & 21 \\
\hline & Poor communication skills & 12 \\
\hline & Too strict & 5 \\
\hline & Stays in the same position in class & 3 \\
\hline & Only asks questions from very smart students & 4 \\
\hline & Coming late to class & 6 \\
\hline & Does not teach according to their learning style & 18 \\
\hline & Does not engage students in class & 37 \\
\hline \multirow{3}{*}{$\begin{array}{l}\text { Reasons } \\
\text { associated } \\
\text { with student }\end{array}$} & Not prepared for class & 11 \\
\hline & Easily distracted & 38 \\
\hline & Personal problems & 10 \\
\hline \multirow{22}{*}{$\begin{array}{l}\text { Reasons } \\
\text { associated } \\
\text { with course }\end{array}$} & Private matters & 3 \\
\hline & Tiredness & 13 \\
\hline & Lack of motivation & 8 \\
\hline & Bored & 26 \\
\hline & Late evening class & 3 \\
\hline & Financial issues & 10 \\
\hline & Too many friends & 26 \\
\hline & Short attentions span & 16 \\
\hline & Multitasking & 28 \\
\hline & Feels disconnected from teaching & 14 \\
\hline & Class too long with no break & 5 \\
\hline & Wanting to check something online & 11 \\
\hline & Course is too difficult & 19 \\
\hline & Unnecessary content & 23 \\
\hline & Uninteresting content & 24 \\
\hline & Unimportant content & 4 \\
\hline & Course objectives were not clear & 3 \\
\hline & Too much notes & 3 \\
\hline & Not enough time to complete class assignments & 2 \\
\hline & Course is too easy & 3 \\
\hline & Don't like course & 4 \\
\hline & Compulsory to take course & 3 \\
\hline \multirow{5}{*}{$\begin{array}{l}\text { Reasons } \\
\text { associated } \\
\text { with learning } \\
\text { environment }\end{array}$} & Access to computers with Internet & 21 \\
\hline & Seating arrangements & 4 \\
\hline & Poor lighting & 1 \\
\hline & Crowded classroom & 6 \\
\hline & Noisy classroom & 4 \\
\hline
\end{tabular}

multitasking. Distraction in the classroom can emerge from different areas. However, if a teacher tends to discuss unrelated course issues for too long, learners are likely to cyberloaf. Other distractions such learners keeping their phones loud, or on vibration, poor classroom seating arrangements may cause distraction. Students involved in multitasking were seen to think they had the skill of accessing the internet while simultaneously listening to the lectures. But, alternating between two tasks at the same time caused students to lose concentration when listening as the lecturer did not have their attention. Regarding the course related reasons, students mentioned unnecessary content, 
120

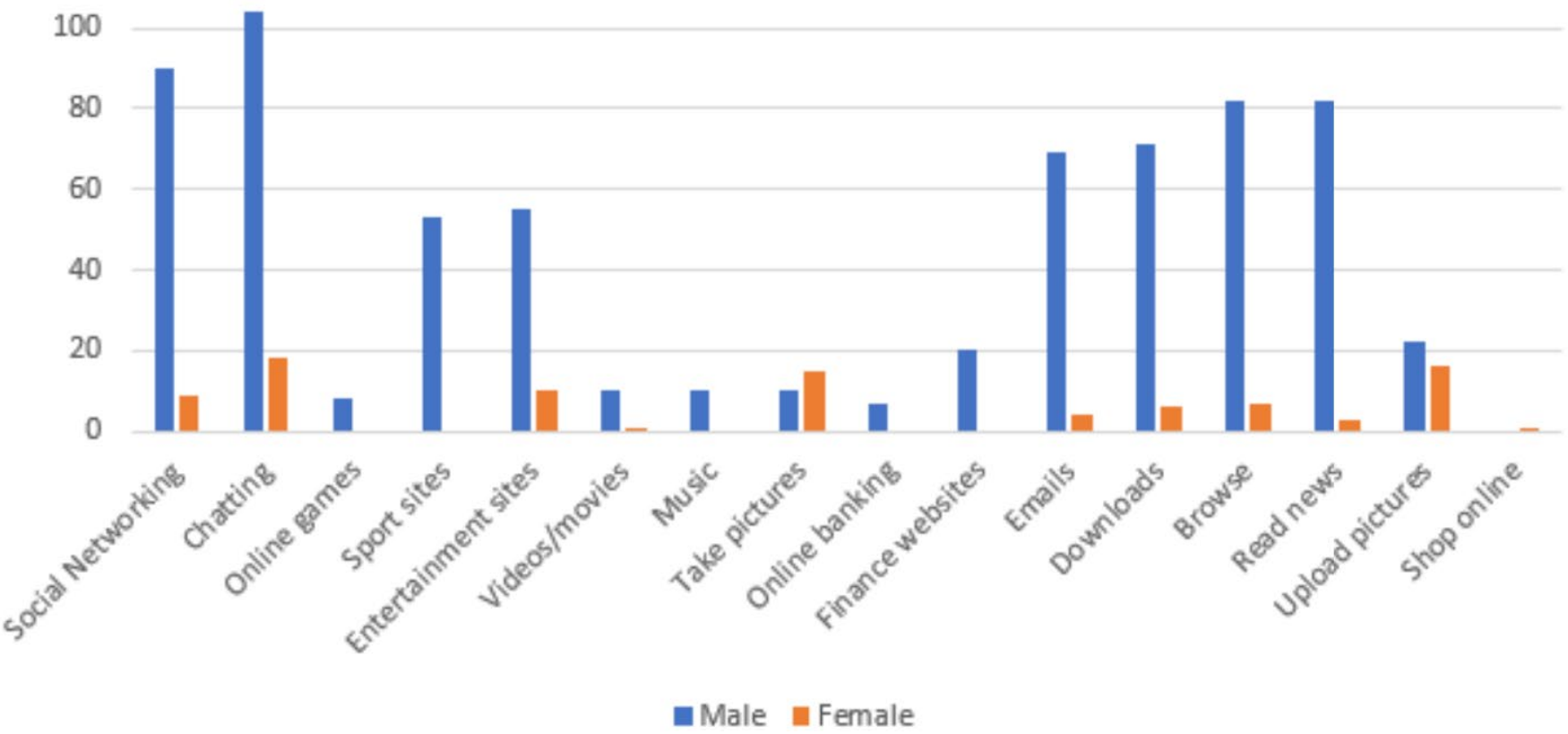

Figure 1. Cyberloafing Activities by Gender

uninteresting content and difficult content as reasons why they cyberloaf. Here it is assumed that students do cyberloaf when the content is not interesting and that could be tracked to the relatedness. No wonder most lectures complain that is those who teach concrete and relatedness courses score higher on student appraisal than those who teach abstract course (Kwarteng et al., 2016). Learners conclude on content irrelevance mostly if they cannot relate the content to its use outside of the school or at work. In education, it is assumed that students in the pre-tertiary levels engage in conversation and those were found in classes where learners could not extract the practical value of what they learn (Anyagre, 2009). Finally, on the reasons related to the learning environment, respondents mentioned that the main motivating factor is the fact that they have access to computers. The student factors that respondents indicated were access to computer. Thus learners assume that if such facilities are unavailable during lectures, it will curb cyberloafing by default.

Research Question 3: What Is the Level of University Student's Involvement in Cyberloafing Activities Based on Gender?

The third research question sought to find out which gender group was more involved in cyberloafing activities during lectures. To answer this research question, data gathered from both male and female students who were involved in the study were used. Figure 1 indicates the results of cyberloafing activities based on gender.

From Figure 1, it could be seen that males engage in cyberloafing activities more than female. In this study, cyberloafing activities such as listening to music, going to sports and financial websites as well as playing online games were male biased and no female mentioned partaking in such. Most females engaged in chatting online, taking as well as uploading pictures. Males as well engaged greatly in chatting online, visiting social networks and reading of news. Some also engaged in visiting websites in sports, finance and entertainment. Only one female was seen to be engaged in online shopping. The finding also confirmed the those of several other studies that reported that male participants surpassed their female counterparts in cyberloafing scores (See for example: Askew, 2012; Baturay \& Toker, 2015; Lim \& Chen, 2012). Sports is actually a male activity in Ghana because of our cultural roles. In this study, results of cyberloafing activities such as listening to music, going to sports and financial websites as well as playing online games, no female was observed to be partaking in such. Sports is not a female game in Ghana. Ladan (2009) opined that, for many years, society maintained a greater degree of sports competition for boys than for girls. In recent years, there have been many change in women's participation in sports, but the rate of change has been found to be extremely low. The low rate of women involvement in sports is not due to lack of interest but instead, it is due to the long history of direct and indirect forms of discrimination and stereo-typing that women have to contend with (Adeyanju, 2011). Adler (2008) explained that, today as in the past most female members of the society have fewer opportunities in life compared to their male counterparts as they are expected to run a home and bring up children. Women have less free time in their choice of leisure activities and they are more restricted than males. In summary, the finding in research question 3 maintains that more men engage in cyberloafing actions than women, and the nature of cyber actions differ between men and women. Women tend to prefer chatting and entertainment activities whereas men tend engage more in sports related actions.

\section{CONCLUSION AND RECOMMENDATIONS}

The current study broadens our understanding of the frequency, nature, kinds and gender issues in cyberloafing activities among university students. Although cyberloafing 
was reported as a frequently practiced action among students, the kinds of cyberloafing activities students engage in were narrowed to some specific activities which differ slightly from what has been reported in literature. The common cyberloafing actions among Ghanaian university students as shown here were chatting online, visiting social networks, surfing the internet and reading news. In terms of gender, males were found to participate in cyber actions during lectures more than females. Again, the kinds of cyber activities females engaged in were quite different from those of the male students and this was interpreted as a function of the cultural orientations. Further, and more of concern were the reinforcers of cyberloafing. All the elements in the classroom ranging from the teacher, learner, course content and learning environment were potential sources of reinforcement to cyberloafing. Poor preparation, inadequate student engagement and use of TLMs were chief teacher flaws that could trigger cyberloafing among students. Hitherto, it was assumed that the inadequacy of TLMs only impairs students understanding. However, the present study broadens our perspective that insufficient use of TLMs do not only impede the rate of understanding, but also reinforces cyberloafing. Also, depending on the lecture method alone turns out stifling students engage at lessons. Lectures may probably have to adopt multi-pedagogical skills in order to attract and sustain learner's attention. Also, lecturers are encouraged to involve students in the teaching. Asking students questions, causing them to take assignments are all activities that can sustain their attention and hence minimise cyberloafing. Students optimism that they can multitask was the learner factor that drive cyberloafing. It is therefore important to sensitise students on attention and distraction issues.

Effective ways such as organization of the classroom environment, lecturers varying their teaching methods and techniques and keeping students' attention by making content more interesting and interactive would go a long way to reduce cyberloafing activities. Thus, it has also become very necessary for lecturers to be aware, understand and manage the cyberloafing activities during lecture hours. Notwithstanding, a study into the strategies to reduce cyberloafing among university students is warranted, in which students and management can examine on the appropriate strategies to curb this menace.

Author contributions: All co-authors have involved in all stages of this study while preparing the final version. They all agree with the results and conclusions.

Funding: No external funding is received for this article.

Declaration of interest: The authors declare that they have no competing interests.

Ethics approval and consent to participate: Not applicable.

Availability of data and materials: All data generated or analyzed during this study are available for sharing when appropriate request is directed to corresponding author.

\section{REFERENCES}

Adeyanju, F. B. (2011). Women and sports in Nigeria: problems and prospects in the $21^{\text {st }}$ century. Retrieved 27 December 2020 from http://www.onlinenigeria.com
Adler, J. (2008) Social changes and women in African sports. Journal of Social Sciences. 2(1), 50-53.

Askew, K. L. (2012). The relationship between cyberloafing task and performane and an examination of the theory of planned behavior as a model of cyberloafing (Doctoral dissertation, University of South Florida). https://www.google. com/search?q=Askew

Baturay, M. H., \& Toker, S. (2015). An investigation of the impact of demographics on cyberloafing from an educational setting angle. Computers in Human Behavior, 50, 358-366. https://doi.org/10.1016/j.chb.2015.03.081

Boakye, K. B., \& Banini, D. A. (2008). Teacher technology Readiness in Ghana. In K. Toure, T. M. S. Tchombe, \& T. Karsenti (Eds.), Technology and Changing Mindsets in Education. Langaa; ERNWACA / ROCARE.

Brubaker, A. T. (2006). Faculty perceptions of the impact of student laptop use in a Wireless internet environment on the classroom learning environment and teaching information and library science (Master Thesis), University of North Carolina, North Carolina.

Chawinga, W. (2017). Taking social media to a university classroom: teaching and learning using twitter and blogs. International Journal of Educational Technology in Higher Education, 14, Article 3. https://doi.org/10.1186/s41239017-0041-6

Coskun, T. K., \& Gokcearslan, S. (2019). Examination of cyberloafing studies in education: A content analysis. World Journal on Educational Technology: Current Issues, 11(1), 94-103. https://doi.org/10.18844/wjet.v11i1.4017

Dursun, O. O., Donmez, O., \& Akbulut, Y. (2018). Predictors of cyberloafing among preservice information technology teachers. Contemporary Educational Technology, 9(1), 2241. https://doi.org/10.30935/cedtech/6209

Glass, A. L., \& Kang, M. (2019). Dividing attention in the classroom reduces exam performance. Educational Psychology, 39(3), 395-408. https://doi.org/10.1080/ 01443410.2018 .1489046

Goldhaber, D. (2002). The Mystery of Good Teaching. Education Next, 2(1), 50-55. https://www.educationnext. org/the-mystery-of-good-teaching/

Hembrooke, H., \& Gay, G. (2003). The laptop and the lecture: The effects of multitasking in learning environments. Journal of Computing in Higher Education, 15, 46-64. https://doi.org/10.1007/BF02940852

Jandaghi, G., Alvani, S. M., Matin, H. Z., \& Kozekanan, S. F. (2015). Cyberloafing Management in Organizations. Iranian Journal of Management Studies, 8(3), 335-349.

Karaoglan Yilmaz, F. G., Yilmaz, R., Ozturk, H. T., Sezer, B., \& Karademir, T. (2015). Cyberloafing as a barrier to successful integration and information and communication technologies into teaching and learning environments. Computers in Human Behaviour, 45, 290-298. https://doi.org/10.1016/j.chb.2014.12.023

Krejcie, R. V., \& Morgan, D. W. (1970). Determining sample size for research activities. Educational and Psychological Measurement, 30, 607-610. https://doi.org/10.1177/ 001316447003000308 
Ladan, B. (2009). Psychology of women's participation in competitive sports. Journal of Physical and Health Education, 8(4), 20-23.

Lim, V. K. G., \& Chen, D. J. Q. (2012). Cyberloafing at the workplace: Gain or drain on work? Behaviour and Information Technology, 31(4), 343-353. https://doi.org/ 10.1080/01449290903353054

Marshall, S. (2010). Change, technology and higher education: are universities capable of organisational change? ALT-J, 18(3), 179-192. https://doi.org/10.1080/09687769.2010. 529107

Nwakaego, F. O., \& Angela, O. I. (2018). Influence of cyberloafing on library and information studies students at the university of ibadan, nigeria. Journal of Educational Research and Review, 6(3), 54-60. https://doi.org/ 10.30918/AERJ.63.18.039

Ocansey, K. S., Ametepe, W., \& Oduro, C. F. (2016). Impact on social media on the youth: the Ghanaian perspective. International Journal of Engineering Technology and Sciences, 6(1), 87-97. https://doi.org/10.15282/ijets.6.2016. 1.12 .1062

Porter, A. C., \& Brophy, J. (1988). Synthesis of research on good teaching: Insights from the work of the institute for research on teaching. Educational Leadership, 45(8), 74.

Ragan, E. D., Jennings, S. R., Massey, J. D., \& Doolittle, P. E. (2014). Unregulated use of laptops over time in large lecture classes. Computers \& Education, 78, 78-86. https://doi.org/10.1016/j.compedu.2014.05.002

Raja, R., \& Nagasubramani, P. C. (2018). Impact of modern technology in education. Journal of Applied and Advanced Research, 3(SI), 33. https://doi.org/10.21839/jaar.2018. v3iS1.165

Ravizza, S. M., Uitvlugt, M. G., \& Fenn, K.M. (2017). Logged in and zoned out: how laptop internet use relates to classroom learning. Psychological Science, 28(2), 171-180. https://doi.org/10.1177/0956797616677314
Saritepeci, M. (2020) Predictors of cyberloafing among high school students: unauthorized access to school network, metacognitive awareness and smartphone addiction. Education and Information Technologies, 25, 2201-2219. https://doi.org/10.1007/s10639-019-10042-0

Saroyan, A., Dagenais, J., \& Zhou, Y. (2009). Graduate students' conceptions of university teaching and learning: Formation for change. Instructional Science, 37(6), 579-600. https://doi.org/10.1007/s11251-008-9071-8

Taneja, A., Fiore, V., \& Fischer, B. (2015). Cyber-slacking in the classroom: Potential for digital distraction in the new age. Computers in Education, 82, 141-151. https://doi.org/ 10.1016/j.compedu.2014.11.009

Tutkun, O. F. (2011). Internet access, use and sharing levels among students during teaching-learning process. TOJET the Turkish Online Journal of Educational, 10(3), 152-160.

Varol, F., \& Yıldırım, E. (2019). Cyberloafing in higher education: Reasons and suggestions from students' perspectives. Technology, Knowledge and Learning, 24(1), 129-142. https://doi.org/10.1007/s10758-017-9340-1

Wu, J., Mei, W., \& Ugrin, J. C. (2018). Student cyberloafing in and out of the classroom in china and the relationship with student performance. Cyberpsychology, Behaviour and Social Networking, 21(3), 199-204. https://doi.org/10.1089/ cyber.2017.0397

Yasar, S., \& Yurdugul, H. (2013). The investigation of relation between cyberloafing activities and cyberloafing behaviours in higher education. Procedia- Social and Behavioral Sciences, 83, 600-604. https://doi.org/10.1016/ j.sbspro.2013.06.114

Yebowaah, F. A. (2018). Internet use and its effect on senior high school students in Wa Municipality of Ghana. https://digitalcommons.unl.edu/libphilprac/1817 